\title{
ALCOHOL SEPTAL ABLATION
}

\section{Desislava P. Petrova, Sotir T. Marchev, Boyko D. Kuzmanov}

Specialized Hospital for Active Treatment in Cardiology, Pleven

Corresponding Author:

Desislava P. Petrova

Specialized Hospital for Active

Treatment in Cardiology

91, Gen. Vladimir Vazov Str.

Pleven, 5800

Bulgaria

e-mail:dpetrova@live.com

Received: April 04, 2015

Revision received: August 30, 2015

Accepted: December 01,2015

\section{Summary}

Since 1994, alcohol septal ablation (ASA) has been used as a minimally invasive treatment of patients with hypertrophic obstructive cardiomyopathy, resistant to conservative medical therapy. This catheter-based intervention consists of injecting absolute alcohol in a septal perforator to induce infarction of the hypertrophied septum and thus diminish the left ventricle outflow tract obstruction. This reduction of the gradient is associated with reduction of symptoms and left ventricle remodeling. The procedure was improved after the introduction of myocardial contrast echocardiography for visualization of the area at risk of infarction and reduction of the alcohol amount. Major complications of ASA are rare but centers with experience have reported conduction disorders about $10 \%$ of patients needed permanent pacing because of complete AV block. Large randomized prospective studies have not yet compared alcohol septal ablation to the gold standard for treatment of hypertrophic obstructive cardiomyopathy - surgical myomectomy.

Key words: hypertrophic cardiomyopathy, left ventricular outflow obstruction, alcohol septal ablation

\section{Introduction}

Hypertrophic obstructive cardiomyopathy (HOCMP) is a genetic cardiac disease caused by mutation in the genes of sarcomere proteins, which leads to disarrangement of myocytes with or without fibrosis, hypertrophy and thickening of the media of the intramural arteries. The pattern of inheriting HOCMP is autosomal-dominant. Penetration is agerelated and occurs at rate of 1:500. The disease has a wide spectrum of clinical presentation which may vary from complete lack of symptoms to severe heart failure or sudden cardiac death (SCD). One-year mortality is estimated to be about $1 \%$, mostly due to SCD or terminal heart failure. Approximately $30 \%$ of the patients with HOCMP present with dynamic obstruction in the left ventricle outflow tract (LVOT), which also explains many aspects of the disease [1]. A gradient in the LVOT higher than 30 $\mathrm{mm} \mathrm{Hg}$ is associated with increased risk of progressive heart failure, stroke and death.

According to the guidelines of the European Society of Cardiology, drug therapy in patients with 
HOCMP includes beta blockers and calcium channel antagonists. Between 5 and $10 \%$ of these patients are resistant to conservative treatment. The treatments of choice in these patients are septal myoectomy and alcohol septal ablation (ASA).

\section{Indications for ASA}

Septal myoectomy is indicated in patients, who are highly symptomatic and resistant to optimal drug therapy: dyspnea on physical exertion or chest pain, classified as NYHA III-IV or CCS IIIIV. Additional selection criteria for ASA are thickness of the septum (16 $\mathrm{mm}$ or more), a gradient at rest of $30-60 \mathrm{~mm} \mathrm{Hg}$ or, after provocation, more than 50-60 $\mathrm{mm} \mathrm{Hg}$ [2] (Fig. 1 ). With the development of invasive cardiology and the increasing number of procedures in some centers, ASA has been increasingly recognized as the method of choice for treatment of symptomatic patients with HOCMP, and the scope of indications is widening.

Clinical and echocardiographic evaluation, co-morbidities and other disorders in the cardiac function are important indications for ASA. These disorders could include subaortic stenosis, severe coronary artery disease, and structural abnormalities of the mitral valve and apparatus.

In $10 \%$ of the cases, HOCMP is usually associated with abnormal mitral valve function: abnormal attachment of a papillary muscle to the anterior mitral leaflet, or to the left ventricle free wall, both causing obstruction in the middle part of the ventricle $[3,4]$.
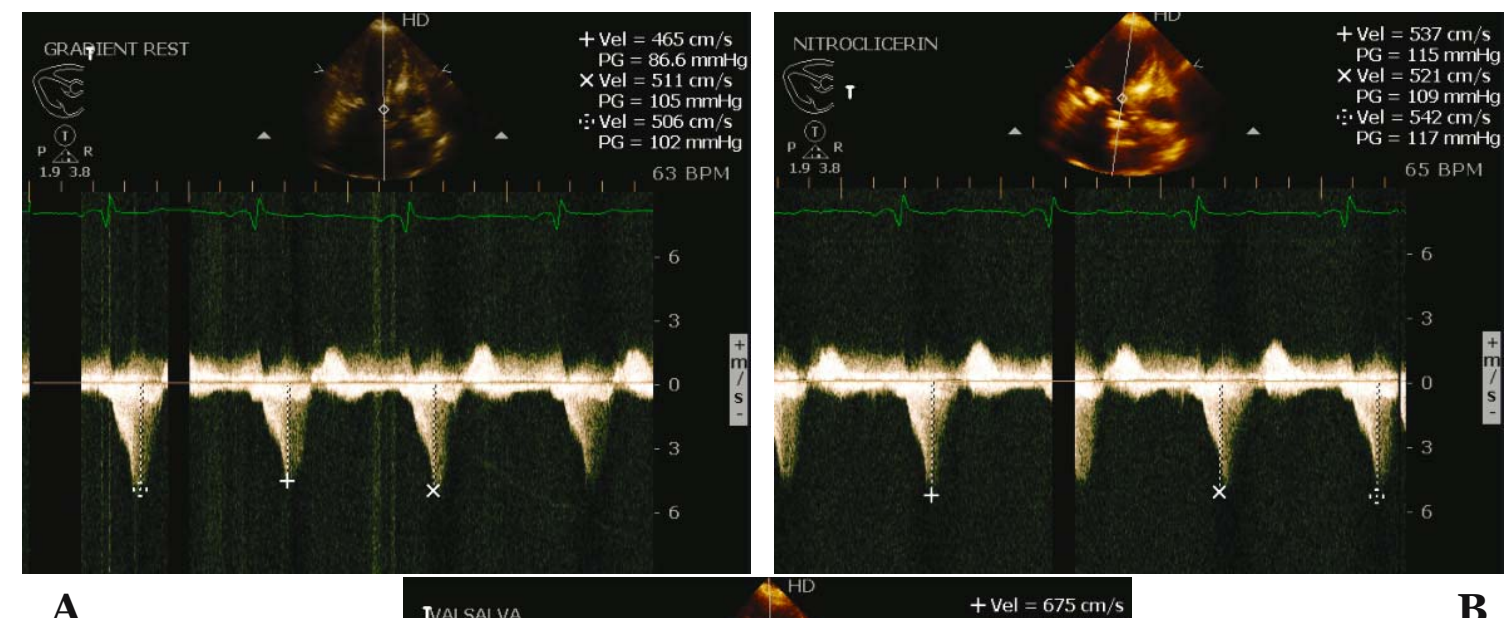

A

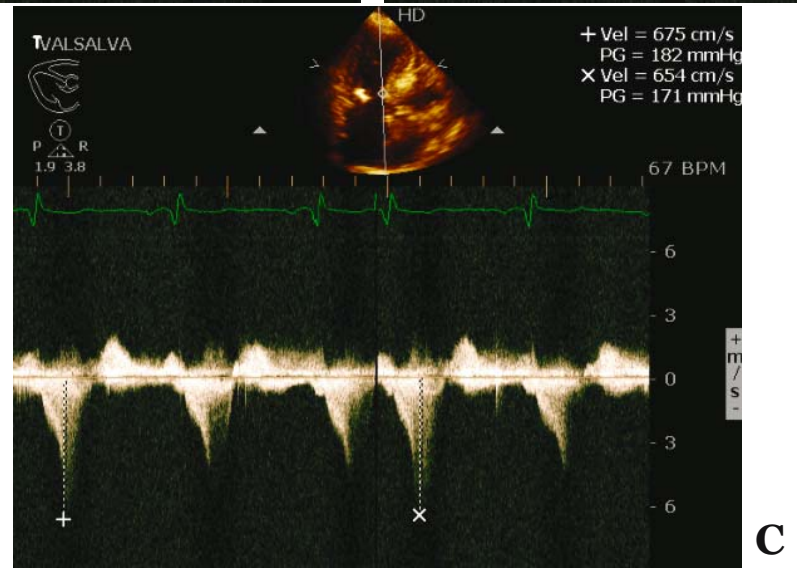

B

Figure 1. CW-Doppler, showing a maximal gradient of $105 \mathrm{mmHg}$ at rest in the LVOT of a 66-year-old patient with HOCMP (A); B. after provocation with nitroglycerin (maximal gradient of $117 \mathrm{~mm} \mathrm{Hg}$; C. after Valsalva (maximal$182 \mathrm{~mm} \mathrm{Hg})$

\section{ASA}

Alcohol septal ablation was first introduced in 1994 as a less invasive procedure than surgical myomectomy in symptomatic patients at high risk for surgery. Since then the procedure has been improved, one improvement being the introduction of a myocardial contrast agent for 
echocardiographic localization of the target area.

Following arterial access, the hemodynamic parameters and the intraventricular gradient are measured simultaneously, with pig-tail catheters in the left ventricle cavity and in the aorta (Fig. 2).
Then gradients are measured after Valsalva maneuver, after provocation of extrasystole and after intravenous injection of a vasodilatator (nitrate) (Fig. 3).

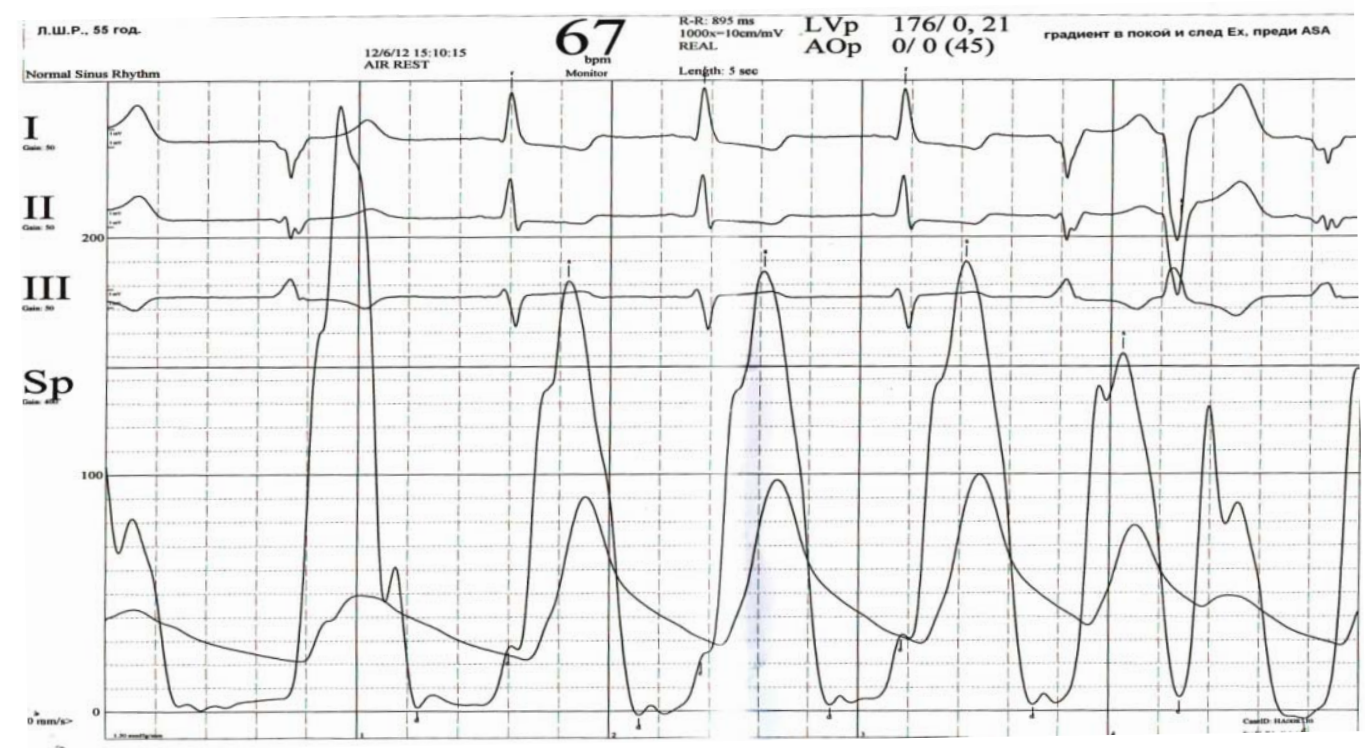

Figure 2. A55-year- old patient with HOCMP. Simultaneous measurement of the pressure in the left ventricle and in the aorta with a gradient in the LVOT of $190 \mathrm{~mm} \mathrm{Hg}$ after an extrasystole

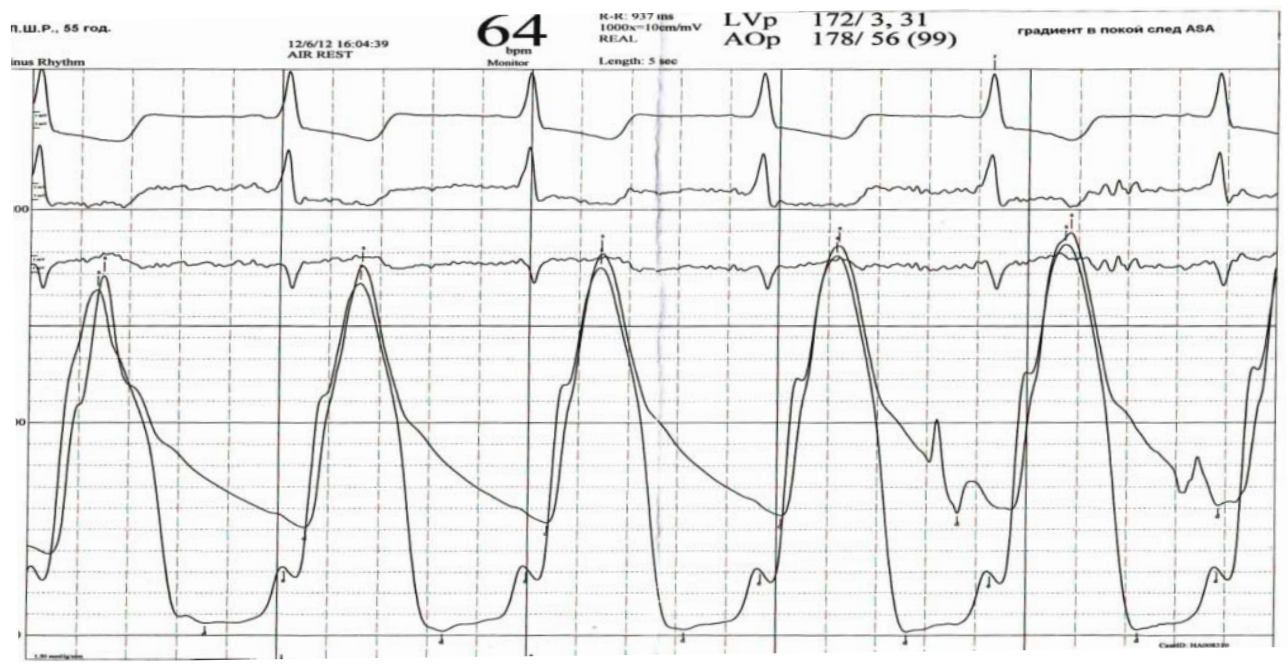

Figure 3. Simultaneous measurement of the pressure in the left ventricle of the same patient right after ASA showing no gradient in the LVOT

Coronary angiography is performed to exclude severe coronary artery disease and to localize the first septal perforator branch. It usually arises from the left anterior descending artery (LAD) but could also originate from the left main, from an intermediate branch, from the left circumflex artery or even from the right coronary artery. The septal branch is cannulated with an over-the-wire balloon, whose lumen serves for injecting the contrast agent and alcohol. The balloon is inflated to prevent backflow to the main artery. Backflow is checked by injecting a contrast agent. Due to anatomical variations of the septal perforator, it could supply not only the basal septum, but also the right ventricle septum, the left ventricle apex, and papillary muscle [4]. The echocardiographic guidance of the procedure for detecting the area of risk is a key point for 
success. Usually the area of interest is the basal septum, where it contacts with the anterior mitral leaflet in systole. The echo contrast is injected through the balloon. At the same time, the area perfused by the target vessel is echocardiographically detected [5, 6] (Fig. 4).

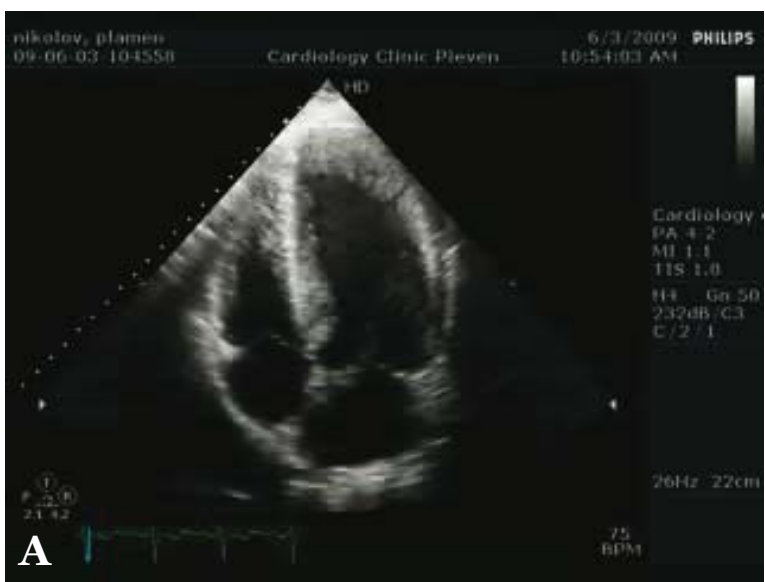

Patients with larger area of risk, including the right ventricle septum, have a higher percentage of complications [7]. If the perforator supplies a large region, a smaller amount of alcohol could be used. If it has sub-branches, only those supplying the basal septum should be ablated.

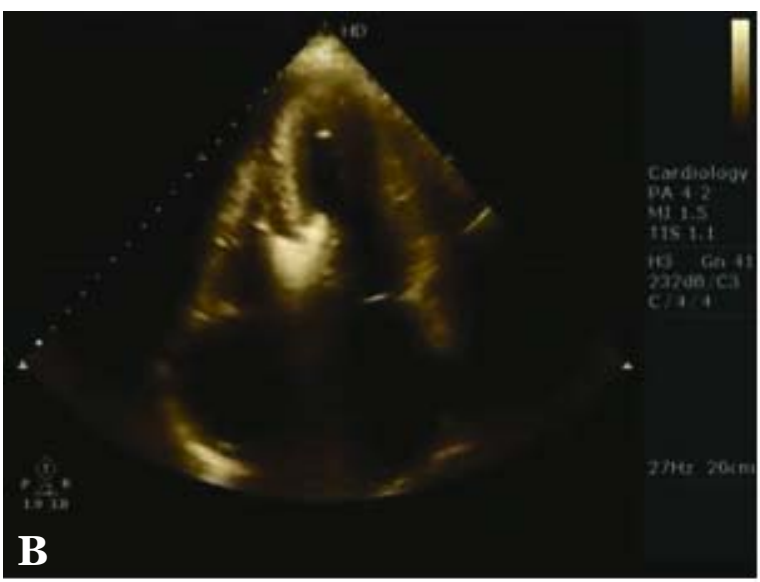

Figure 4. A 45 year-old patient with HOCMP; A: 4-chamber view demonstrating the hypertrophic basal septum; B: opalescence of the basal septum after injecting contrast agent in the first septal branch

Before proceeding with alcohol septal ablation, a temporary pacemaker is introduced (usually via the femoral vein), and an analgesic and oxygen are injected i.v. Then absolute alcohol is injected through the inflated balloon. After 10 minutes the balloon is deflated, angiography is performed to check the patency of LAD. This usually visualizes an occluded perforator branch.

The dosage of alcohol is widely discussed and varies between 0.5 and 3-4 $\mathrm{ml}$. Lately, studies have shown that a lower dose $(2 \mathrm{ml})$ of alcohol is associated with a reduction of the gradient in the LVOT (Fig. 5). The reduction is identical with the one achieved with higher doses and with symptoms improvement at 6 months [8]. The amount of alcohol correlates with the size of the necrotic area (pick values of creatine phosphokinase $+\mathrm{MB}$ fraction) and is an independent predictor for complications during ASA, as well as for post procedure death [9]. It has also been established that slower injection of the alcohol reduce the risk of complete AV block $[4,10,11]$.
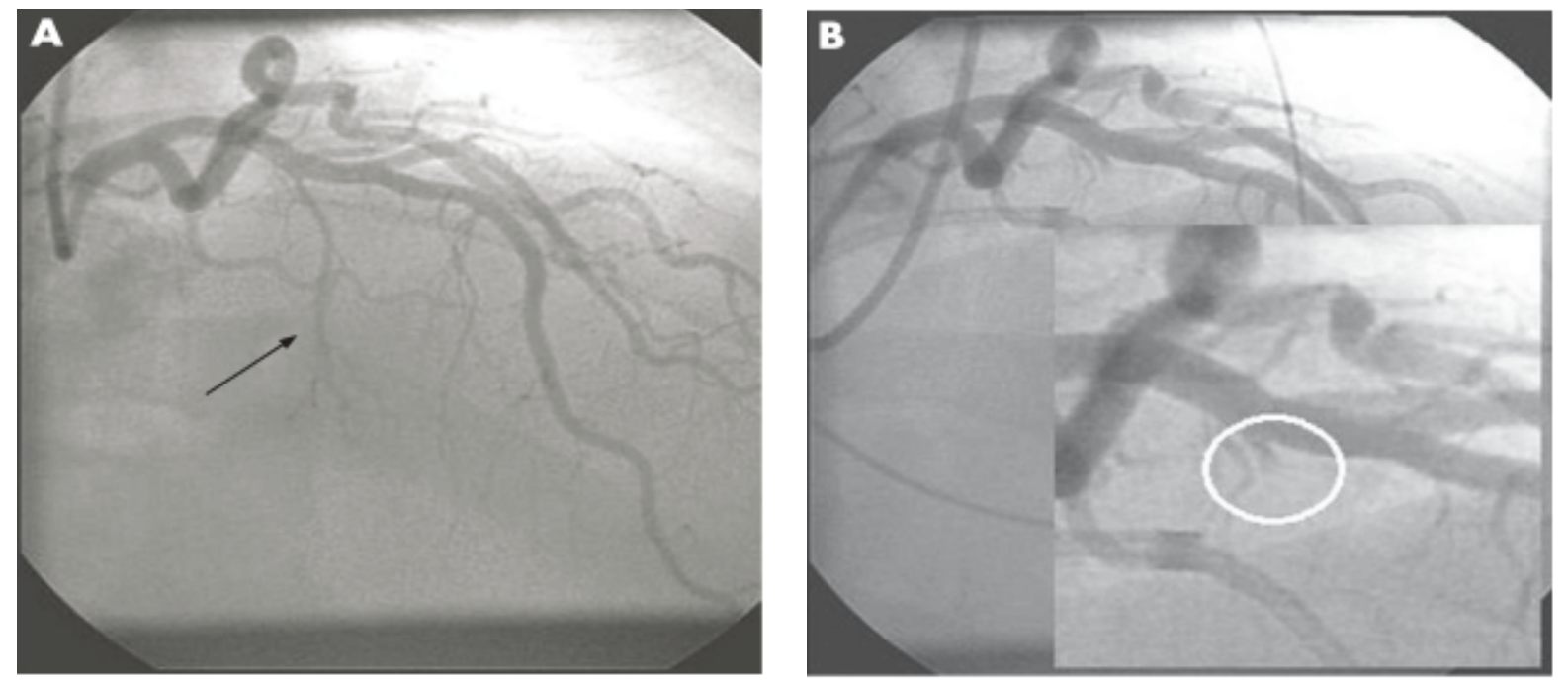

Figure 5. First septal branch before ASA (A), occlusion of the first septal branch after ASA (B) [7] 


\section{Remodeling of the left ventricle and hemodynamics after ASA}

Right after ASA there is a complete drop of the gradient in the LVOT which is a consequence of the stunned myocardium and is different from the late remodeling due to akinesia and thinning of the basal septum. (Fig. 6 [12]) The initial

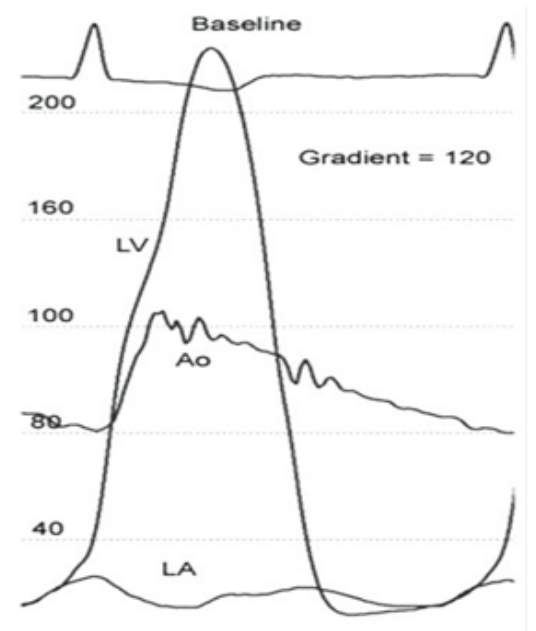

decrease of the gradient could be followed by a paradoxical increase in the first 1 to 3 days. Usually, between the $6^{\text {th }}$ and $12^{\text {th }}$ month there is a stable progressive decrease of the gradient in the LVOT (decrease of the mean gradient from 61 to $31 \mathrm{mmHg}$ [13]), resulting from the formation of a scar and left ventricle remodeling $[14,15,16]$.

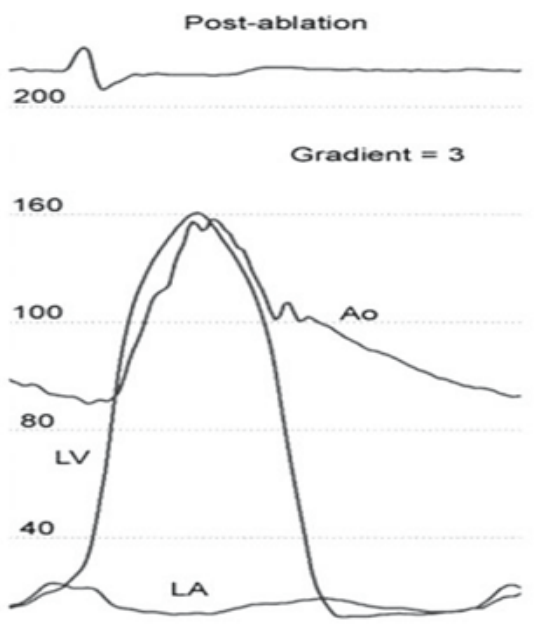

Figure 6. Simultaneous measurement of the gradient in the left atrium (LA), left ventricle (LV) and in the aorta (Ao) before and after successful ASA [12]

ASA is associated with almost complete disappearance of the mitral insufficiency at long term follow-up [21]. Cardiac magnetic resonance and strain-rate imaging were used to assess of the left ventricle remodeling and systolic function. They showed a significant reduction of the left ventricle mass and thickness of the myocardium during follow-up [18-20]. There is also a mild reduction of the left ventricle function with a paradoxical increase of some systolic indices (index of shortening and Tei-index [18, 19]). Many studies have also examined the diastolic function after ASA $[19,20]$. In the latest register of Jassal et al., all patients initially presented with a pseudo-normal or abnormal relaxation and dilated left atrium. During long term follow-up after successful ASA there was significant improvement in the deceleration time of the Ewave, the isovolumetric relaxation time, the early diastolic mitral annular velocity (E'), E/E', and E/Vp [20].

\section{Complications after ASA}

Complications after ASA are rare in centers with experience and could vary from rhythm and cardiac tamponade, cardiogenic shock, pulmonary thromboembolism, and stroke. Among the most common are the conduction disorders. According to literature data, first degree $\mathrm{AV}$ block occurs in $53 \%$ of patients, right bundle branch block in - 46\%, and complete AV block requiring permanent pacing is seen in about $10 \%$ of the cases. Transient complete AV block is seen in 10 to $46 \%$ of the patients during the first 24 hours after the procedure [21, 22], and only a small percentage could develop it to the $9^{\text {th }}$ day after ASA [9, 23]. This influences the length of hospital stay, which varies depending on the number of days needed for intensive monitoring (at least 24-48 hours up to 5 days [3, 22, 24]). Several studies have attempted to define the reasons for developing complete AV- block and thus identify the high risk group, which would benefit from a permanent pacing before the procedure. Age over 55, female gender, bolus injection of alcohol, ablation of more than one septal branch, the amount of alcohol used, and no echocardiographic control have been identified as potential factors. Only the presence of left bundle branch block prior the procedure was found to be a strong predictor for complete AV 
block $[9,25,26]$. Faber et al have suggested a score system based on electrocardiographic markers for disorders in the AV conduction system (PQ- interval, width of the QRS and the heart rate in the beginning), the severity in the left ventricle outflow tract, etc. Based on the risk for developing a complete AV block, the score system identifies three groups of patients: those at low, intermediate and high risk. Low-risk patients risk need a shorter period of monitoring (48 hours); those at high risk should proceed to elective permanent pacing, while those at moderate risk should be monitored and followed up for a longer period [5]. According to current data from registers and studies it is still not known whether patients with LBBB need a prophylactic pacemaker.

Ventricle arrhythmias are also common ventricular extrasystoles, ventricular flutter (2.2\%) or ventricular tachycardia [27-30]. Usually, they occur during the early postprocedural period and are transient, although a small group of patients present with ventricular tachycardia up to 3 weeks after ablation. The mechanism of these arrhythmias is debatable: it is still not clear whether they occur as a result of re-entry around the scar and/or as a consequence of an arrhytmogenic substrate of the disarrayed myofibrilis, which are so common in HOCMP.

Estimated early mortality in the first 30 days after ASA amounts to $1.5 \%$ (range $0-5 \%$ ) and is usually a consequence of the hemodynamic collapse due to ventricle failure or cardiac tamponade, ventricle fibrillation or dissection of LAD [31].

Kuhn and co. followed up 644 patients for a period of 10 years. They reported a significant drop of complications after reducing the dosage of alcohol from $2.9 \mathrm{ml}$ to $0.8 \mathrm{ml}$. The in-hospital mortality declined from $1.8 \%$ to $0.6 \%$ [8].

\section{ASA vs surgical myectomy}

After Sigwart introduced ASA in 1994, it has been performed on thousands of patients with very good short-term results. ASA results in a larger area of necrosis, as compared with myectomy $(16 \pm 7 \mathrm{~g}$. vs $6 \pm 4 \mathrm{~g}$.) and often leads to transmural myocardial infarction with varying localization and depth to the junction of the anterior and inferior segment of the basal septum [30]. In some patients there is an expansion of the infarction to the right-ventricle part of the septum, a residual gradient during follow-up and insufficient symptom relief [32]. Myectomy leads to more precise localization of the resection of the left ventricle septum as compared to the deeper scar from ASA, which could explain the common association of ASA with RBBB, and of myectomy with LBBB. It has also been proved that myectomy carries a lower risk of complete $\mathrm{AV}$ block and the need of permanent pacemaker [33]. However, in myectomy the risk of stroke is higher and the recovery period is longer [34].

There are few registers comparing clinical outcomes in ASA and surgical myectomy, and none to propose comparisons based on long-term follow-up. According to a meta-analysis of three retrospective studies including 171 patients [3538], both interventions have similar effects regarding the reduction the interventricular septum, the increase of the left-ventricle end diastolic diameter, and improvement of the NYHA class [33].

However, some difference has been reported between the decrease of the LVOT gradient achieved: from 76 to $15.7 \mathrm{mmHg}$ in the ASA group vs 74.7 to $9.4 \mathrm{mmHg}$ in the myectomy group $(\mathrm{p}<0.05)$ [33].

\section{Conclusions}

ASA is developing as a safe and attractive alternative for management of patients with HOCMP, whose symptoms are resistant to optimal drug therapy. In the last 10 years the procedure has been improved with the introduction of echocardiographic guidance with contrast agent for localization of the target vessel and visualization of the infarction-risk area. This has led to a significant reduction of complications and the need of permanent pacing as well. There are still insufficient data regarding long-term follow-up after ASA and randomized trials comparing the procedure with classical myectomy.

\section{References}

1. Maron BJ, McKenna WJ, Danielson GK, Kappenberger LJ, Kuhn HJ, Seidman CE, et al. American College of Cardiology/European Society of Cardiology clinical expert consensus document on hypertrophic cardiomyopathy. A report of the American College of Cardiology Foundation Task Force on Clinical Expert Consensus Documents and the European Society of Cardiology Committee for Practice Guidelines. 
J Am Coll Cardiol. 2003;42(9):1687-713.2).

2. Maron BJ, Dearani JA, Ommen SR, Maron MS, Schaff HV, Gersh BJ, et al. The case for surgery in obstructive hypertrophic cardiomyopathy. J Am Coll Cardiol. 2004;44(10):2044-53.

3. Holmes DR Jr., Valeti US, Nishimura RA. Alcohol septal ablation for hypertrophic cardiomyopathy: indications and technique. Catheter Cardiovasc Interv. 2005;66(3):375-89.

4. Singh M, Edwards WD, Holmes DR Jr, Tajil AJ, Nishimura RA. Anatomy of the first septal perforating artery: a study with implications for ablation therapy for hypertrophic cardiomyopathy. Mayo Clin Proc. 2001;76(8):799-802.

5. Faber L, Ziemssen P, Seggewiss H. Targeting percutaneous transluminal septal ablation for hypertrophic obstructive cardiomyopathy by intraprocedural echocardiographic monitoring. J Am Soc Echocardiogr. 2000;13(12):1074-9.

6. Monakier D, Woo A, Puri T, Schwartz L, Ross J, Jamorski $M$, et al. Usefulness of myocardial contrast echocardiographic quantification of risk area for predicting postprocedural complications in patients undergoing septal ethanol ablation for obstructive hypertrophic cardiomyopathy. Am J Cardiol. 2004;94(12):1515-22.

7. Faber L, Seggewiss H, Welge D, Fassbender D, Schmidt HK, Gleichmann U, et al. Echo-guided percutaneous septal ablation for symptomatic hypertrophic obstructive cardiomyopathy: 7 years of experience. Eur J Echocardiogr. 2004;5(5):34755.

8. Chang SM, Nagueh SF, Spencer WH 3rd, Lakkis NM. Complete heart block: determinants and clinical impact in patients with hypertrophic obstructive cardiomyopathy undergoing nonsurgical septal reduction therapy. J Am Coll Cardiol. 2003;42(2):296-300.

9. Kuhn H, Lawrenz T, Lieder F, Leuner C, StrunkMueller C, Obergassel L, et al. Survival after transcoronary ablation of septal hypertrophy in hypertrophic obstructive cardiomyopathy (TASH): a 10 year experience. Clin Res Cardiol. 2008;97(4):234-43.

10. Bhagwandeen R, Woo A, Ross J, Wigle ED, Rakowski H, Kwinter J, et al. Septal ethanol ablation for hypertrophic obstructive cardiomyopathy: early and intermediate results of a Canadian referral centre. Can J Cardiol. 2003;19(8):912-7.

11. Veselka J, Duchonová R, Procházková S, Homolová I, Pálenícková J, Zemánek D, et al. The biphasic course of changes of left ventricular outflow gradient after alcohol septal ablation for hypertrophic obstructive cardiomyopathy. Kardiol Pol. 2004;60(2):133-6.

12. Sorajja P, Valeti U, Nishimura R, Ommen S, Rihal C, Gersh B. Outcome of Alkohol septal ablation of obstructive hypertrophic cardiomiopaty. Circulation. 2008;118:131-139.
13. Angelini P. The "1st septal unit" in hypertrophic obstructive cardiomyopathy: a newly recognized anatomo-functional entity, identified during recent alcohol septal ablation experience. Tex Heart Inst J. 2007;34(3):336-46.

14. Yoerger DM, Picard MH, Palacios IF, Vlahakes GJ, Lowry PA, Fifer MA. Time course of pressure gradient response after first alcohol septal ablation for obstructive hypertrophic cardiomyopathy. Am J Cardiol. 2006;97(10):1511-4.

15. Henein MY, O'Sullivan CA, Ramzy IS, Sigwart U, Gibson DG. Electromechanical left ventricular behavior after nonsurgical septal reduction in patients with hypertrophic obstructive cardiomyopathy. J Am Coll Cardiol. 1999;34(4):1117-22.

16. van Dockum WG, Kuijer JP, Götte MJ, Ten Cate FJ, Ten Berg JM, Beek AM, et al. Septal ablation in hypertrophic obstructive cardiomyopathy improves systolic myocardial function in the lateral (free) wall: a follow-up study using CMR tissue tagging and 3D strain analysis. Eur Heart J. 2006;27(23):2833-9.

17. van Dockum WG, Beek AM, ten Cate FJ, ten Berg JM, Bondarenko O, Götte MJ, et al. Early onset andprogression of left ventricular remodeling after alcohol septal ablation in hypertrophic obstructive cardiomyopathy. Circulation. 2005;111(19): 25038.

18. Mazur W, Nagueh SF, Lakkis NM, Middleton KJ, Killip D, Roberts R, et al. Regression of left ventricular hypertrophy after nonsurgical septal reduction therapy for hypertrophic obstructive cardiomyopathy. Circulation. 2001;103(11):14926.

19. Veselka J, Prochazkova S, Bolomova-Homolova I, Duchonova R, Tesar D. Effects of alcohol septal ablation for hypertrophic obstructive cardiomyopathy on Doppler Tei index: a midterm follow-up. Echocardiography. 2005;22(2):105-9.

20. Nagueh SF, Lakkis NM, Middleton KJ, Killip D, Zoghbi WA, Quiñones MA, et al. Changes in left ventricular diastolic function 6 months after nonsurgical septal reduction therapy for hypertrophic obstructive cardiomyopathy. Circulation. 1999;99(3):344-7.

21. El-Jack SS, Nasif M, Blake JW, Dixon SR, Grines CL, O'Neill WW. Predictors of complete heart block after alcohol septal ablationfor hypertrophic cardiomyopathy and the timing of pacemaker implantation. J Interv Cardiol. 2007;20(1):73-6.

22. Faber L, Welge D, Fassbender D, Schmidt HK, Horstkotte D, Seggewiss H. Percutaneous septal ablation for symptomatic hypertrophic obstructive cardiomyopathy: managing the risk of procedurerelated AV conduction disturbances. Int J Cardiol. 2007;119(2):163-7.

23. Faber L, Seggewiss H, Welge D, Fassbender D, Ziemssen P, Schmidt HK, et al. Predicting the risk 
of atrioventricular conduction lesions after percutaneous septal ablation for obstructive hypertrophic cardiomyopathy. Z Kardiol. 2003;92(1):39-47.

24. Knight CJ. Alcohol septal ablation for obstructive hypertrophic cardiomyopathy. Heart. 2006;92(9):1339-44.

25. Gietzen FH, Leuner CJ, Raute-Kreinsen U, Dellmann A, Hegselmann J, Strunk-Mueller C, et al. Acute and longterm results after transcoronary ablation of septal hypertrophy TASH). Catheter interventional treatment for hypertrophic obstructive cardiomyopathy. Eur Heart J. 1999;20(18):1342-54.

26. Kuhn H, Seggewiss H, Gietzen FH, Boekstegers P, Neuhaus L, Seipel L. Catheter-based therapy for hypertrophic obstructive cardiomyopathy. First in-hospital outcome analysis of the German TASH Registry. Z Kardiol. 2004;93(1):23-31.

27. Hori Y, Ueda M, Nakayama T, Saegusa N, Uehara $\mathrm{M}$, Lee K, et al. Occurrence of de novo sustained monomorphic ventricular tachycardia induced after percutaneous transluminal alcohol septal myocardial ablation for hypertrophic obstructive cardiomyopathy. Int J Cardiol. 2007;119(3):4037.

28. Simon RD, Crawford FA 3rd, Spencer WH 3rd, Gold MR. Sustained ventricular tachycardia following alcohol septal ablation for hypertrophic obstructive cardiomyopathy. Pacing Clin Electrophysiol. 2005;28(12):1354-6.

29. Boltwood CM Jr., Chien W, Ports T. Ventricular tachycardia complicating alcohol septal ablation. N Engl J Med. 2004;351(18):1914-5.

30. McGregor JB, Rahman A, Rosanio S, Ware D, Birnbaum Y, Saeed M. Monomorphic ventricular tachycardia: a late complication of percutaneous alcohol septal ablation for hypertrophic cardiomyopathy. Am J Med Sci. 2004;328(3):185-8.

31. Alam M, Dokainish H, Lakkis N. Alcohol septal ablation for hypertrophic_obstructive cardiomyopathy: a systematic review of published studies. J Interv Cardiol. 2006;19(4):319-27.
32. van Dockum WG, ten Cate FJ, ten Berg JM, Beek AM, Twisk JW, Vos J, et al. Myocardial infarction after percutaneous transluminal septal myocardial ablation in hypertrophic obstructive cardiomyopathy: evaluation by contrast-enhanced magnetic resonance imaging. J Am Coll Cardiol. 2004;43(1):27-34.

33. Zeng Z, Wang F, Dou X, Zhang S, Pu J. Comparison of percutaneous transluminal septal myocardial ablation versus septal myectomy for the treatment of patients with hypertrophic obstructive cardiomyopathy--a meta analysis. Int J Cardiol. 2006;112(1):80- 4 .

34. Fifer MA. Controversies in cardiovascular medicine. Most fully informed patients choose septal ablation over septal myectomy. Circulation. 2007;116(2):207-16.

35. Nagueh SF, Buergler JM, Quinones MA, Spencer WH 3rd, Lawrie GM. Outcome of surgical myectomy after unsuccessful alcohol septal ablation for the treatment of patients with hypertrophic obstructive cardiomyopathy. J Am Coll Cardiol. 2007;50(8):795-8.

36. Ralph-Edwards A, Woo A, McCrindle BW, Shapero JL, Schwartz L, Rakowski H, et al. Hypertrophic obstructive cardiomyopathy: comparison of outcomes after myectomy or alcohol ablation adjusted by propensity score. J Thorac Cardiovasc Surg. 2005;129(2):351-8.

37. Nagueh SF, Ommen SR, Lakkis NM, Killip D, Zoghbi WA, Schaff HV, et al. Comparison of ethanol septal reduction therapy with surgical myectomy for the treatment of hypertrophic obstructive cardiomyopathy. J Am Coll Cardiol. 2001;38(6):1701-6.

38. Firoozi S, Elliott PM, Sharma S, Murday A, Brecker SJ, Hamid MS, et al. Septal myotomymyectomy and transcoronary septal alcohol ablation in hypertrophic obstructive cardiomyopathy. A comparison of clinical, haemodynamic and exercise outcomes. Eur Heart J. 2002;23(20):1617-24. 